\title{
SUBCLAVIAN FLAP ANGIOPLASTY: DOES THE ARCH LOOK AFTER ITSELF?
}

Marjan Jahangiri, FRCS ${ }^{\text {a }}$

Elliot A. Shinebourne, FRCPa

David Zurakowski, $\mathrm{PhD}^{\mathrm{b}}$

Michael L. Rigby, FRCPa

Andrew N. Redington, FRCP

Christopher Lincoln, FRCS ${ }^{a}$
Objectives: We sought to assess the early and long-term results of subclavian flap angioplasty in neonates and infants, with particular attention to growth of the hypoplastic arch.

Methods: A retrospective analysis of 185 consecutive patients who underwent subclavian flap angioplasty between 1974 and 1998 was carried out. The patients included 125 neonates and 60 infants, with a median age of 18 days. Sixty-six (36\%) patients had an additional ventricular septal defect, 41 (22\%) patients had aortic arch hypoplasia diagnosed preoperatively, 141 (76\%) had an associated patent ductus arteriosus, and $41(22 \%)$ had additional complex heart disease. Follow-up was with transthoracic Doppler echocardiography in all patients.

Results: The early mortality was 3\%. Recoarctation, defined as a Doppler gradient of $25 \mathrm{~mm} \mathrm{Hg}$ or more, occurred in 11 (6\%) patients at a median follow-up of 6.2 years $(6.2 \pm 4.6$ years $)$. This included 4 of the 41 patients in whom arch hypoplasia was diagnosed preoperatively. There were no complications with the left arm. By multivariate analysis, risk factors for death were determined to be residual arch hypoplasia and low birth weight. The only risk factor for recoarctation was persistent arch hypoplasia after surgical treatment. However, angiographic imaging of the aorta showed that recoarctation was not due to a hypoplastic transverse arch, and it was probably at the site of ductal tissue. Survival at 5 and 10 years was $98 \%$ and $96 \%$, respectively. Freedom from reoperation for recoarctation at 2 years was $95 \%$, and at 5, 10, and 15 years, it was $92 \%$.

Conclusions: Subclavian flap repair remains an effective technique for repair of aortic coarctation with excellent results and low mortality. In the majority of patients, arch hypoplasia regresses after this procedure. (J Thorac Cardiovasc Surg 2000;120:224-9)
T he surgical management of neonatal and infantile coarctation of the aorta continues to evolve. In 1945, Gross and Hufnage ${ }^{1}$ at Children's Hospital in Boston reported resection and end-to-end anastomosis. In a report of 500 patients who underwent end-to-end anastomosis repair, Schuster and Gross ${ }^{2}$ expressed concern

From the Department of Pediatric Cardiology and Cardiac Surgery, Royal Brompton Hospital, ${ }^{\text {a }}$ London, United Kingdom, and the Department of Biostatistics, Children's Hospital, ${ }^{\mathrm{b}}$ Boston, Mass. Received for publication Dec 22, 1999; revisions requested Feb 17, 2000; revisions received March 29, 2000; accepted for publication April 4, 2000.

Address for reprints: Elliot A. Shinebourne, FRCP, Department of Pediatric Cardiology, Royal Brompton Hospital, Sydney St, London SW3 6NP, United Kingdom.

Copyright () 2000 by The American Association for Thoracic Surgery

$0022-5223 / 2000 \$ 12.00+0 \quad \mathbf{1 2 / 1 / 1 0 7 6 8 7}$

doi: $10.1067 / \mathrm{mtc} .2000 .107687$ about limited growth potential of the circumferential anastomosis. In 1966, Waldhausen and Nahrwold ${ }^{3}$ reported subclavian flap angioplasty (SFA), which became the method of choice in many centers. With successful repair of transposition of the great arteries and lessening fear of a circumferential anastomosis, together with concern about arch hypoplasia, the endto-end anastomosis repair and modified or extended end-to-end anastomosis has regained popularity. It remains unclear, however, whether end-to-end anastomosis or SFA is the technique of choice. No randomized trials have been published, and the follow-up of some of the newer modifications of end-to-end anastomosis repair is short. We report our experience with a standardized technique for subclavian flap repair over a 24-year period. This study is unique because, at follow-up, recoarctation was assessed in all patients by means of transthoracic echocardiography with Doppler studies. ${ }^{4}$ 


\section{Methods}

Patient population. Between January 1974 and December 1998, 185 patients underwent SFA for coarctation of the aorta at The Royal Brompton Hospital under the care of one surgical team. The patients were referred to the duty surgical service, and therefore there was no potential for selection bias. There were $125(68 \%)$ neonates ( $\leq 30$ days) and $60(32 \%)$ infants. Sixty-four $(35 \%)$ were girls, and $121(65 \%)$ were boys. Fifty-two (28\%) patients underwent an operation between 1974 and 1985, and $133(72 \%)$ patients underwent an operation between 1986 and 1998. The median age at the time of the operation was 18 days. The median age for the neonates was 8 days. The median weight for all patients was $3.6 \mathrm{~kg}$ (range, 1.2-10.0 kg), and the median weight for neonates was $3.3 \mathrm{~kg}$ (range, 1.2-5.6 kg). Diagnosis of coarctation of the aorta in all patients was the indication for surgical treatment. This diagnosis was made in all patients by transthoracic echocardiography. Eighteen $(10 \%)$ patients also underwent cardiac catheterization. Catheterization was performed in the earlier part of the study and in patients with associated cardiac anomalies. Sixty-three (34\%) patients were receiving alprostadil (prostaglandin) infusions before the operation. Twenty-two (12\%) patients were in heart failure and required assisted ventilation before the operation. None of the patients had evidence of a cerebral hemorrhage. Four (2\%) patients had sepsis confirmed by positive blood cultures.

Associated cardiac anomalies. Associated cardiac anomalies are shown in Table I. Ventricular septal defects (VSDs) were classified according to their size and number; small, moderate, or large size (nonlimiting); and single or multiple status.

Arch hypoplasia. The aortic arch was assessed at 3 different times: (1) in the preoperative period by transthoracic echocardiography, (2) by the surgeon at the time of the operation, and (3) in the follow-up period by transthoracic echocardiography, cardiac catheterization, or magnetic resonance imaging. We have defined hypoplasia of the distal arch according to the criteria of Moulaert and colleagues ${ }^{5}$; that is, the diameter of the aorta between the common carotid and left subclavian arteries was less than $50 \%$ of the diameter of the ascending aorta. Arch hypoplasia was present in $41(22 \%)$ patients. This was diagnosed in all by preoperative transthoracic echocardiography and subsequently confirmed at the time of the operation. Patients with an interrupted aortic arch were excluded from the study.

Surgical technique. Before the operation, pressure was measured in the right radial artery and the right or left femoral artery. All patients underwent repair through a left-sided posterolateral thoracotomy. The aortic arch, subclavian artery, aortic isthmus, and descending thoracic aorta were exposed and dissected free. The ductus was divided, clipped, or both, with a clip (Ligaclip; Ethicon Endo-Surgery, Cincinnati, Ohio). The left subclavian artery was ligated in its very distal segment before its first branch. An incision was made just over the descending thoracic aorta distal to the coarctation of
Table I. Associated cardiac anomalies

\begin{tabular}{lc}
\hline Anomaly & No. $(\%)$ \\
\hline VSD & $66(36)$ \\
$\quad$ Small & $41(62)$ \\
Moderate & $7(11)$ \\
Large & $15(23)$ \\
Multiple & $3(5)$ \\
Bicuspid aortic valve & $33(18)$ \\
Atrial septal defect & $22(12)$ \\
Mitral valve anomaly & $14(8)$ \\
Subaortic stenosis & $6(3)$ \\
Aortic valve stenosis & $4(2)$ \\
Discordant ventriculoarterial connection & $6(3)$ \\
Absent right atrioventricular connection & $2(1)$ \\
Double-inlet left ventricle & $4(2)$ \\
Double-outlet right ventricle & $4(2)$ \\
Taussig-Bing anomaly & $1(1)$ \\
\hline
\end{tabular}

the aorta area. This is extended across the coarctation area into the subclavian artery. We extended the aortotomy at least $5 \mathrm{~mm}$ distal to the coarctation of the aorta, so that the distal end of the aortotomy (ie, the site of the distal anastomosis) does not lie opposite the ductal area. Before anastomosing the flap, we excised any excessive ductal tissue that protruded into the lumen of the aorta. All operations were performed by this technique. A single surgeon (C.L.) operated on 128 $(69 \%)$ patients and his trainees operated on the remaining 57 $(31 \%)$ patients.

Follow-up in the early postoperative period. Seventyfour $(40 \%)$ patients underwent transthoracic echocardiography before discharge from the hospital.

Follow-up after hospital discharge. All patients were seen by the referring cardiologist at The Royal Brompton Hospital or by one of the cardiologists in an outreach clinic. Follow-up was complete and up to date in all patients.

Recoarctation. Recoarctation was assessed by means of clinical examination, transthoracic echocardiography, or both. Recoarctation was defined when the arm-leg blood pressure difference was greater than $20 \mathrm{~mm} \mathrm{Hg}$ or if a gradient of more than $25 \mathrm{~mm} \mathrm{Hg}$ was noted by means of transthoracic echocardiography, the presence of a diastolic tail to the continuous wave Doppler signal in the descending aorta, or both. ${ }^{4}$

Statistical analysis. The outcome variables were survival and recoarctation. Univariate analyses for categoric predictors were evaluated by the Fisher exact test. Actuarial estimates for survival and freedom from recoarctation with $95 \%$ Greenwood confidence intervals (CIs) were determined by the Kaplan-Meier product-limit method. Survival curves were compared by the log-rank test. ${ }^{6}$ The Cox proportional hazards regression model was used to establish the variables that were independently associated with each outcome, with risk measured by the hazard ratio using $95 \%$ confidence limits. ${ }^{7}$ For survival analysis, recoarctation was tested as a timedependent covariate in the Cox model. Other covariates included age as both a continuous and categoric (neonates vs 


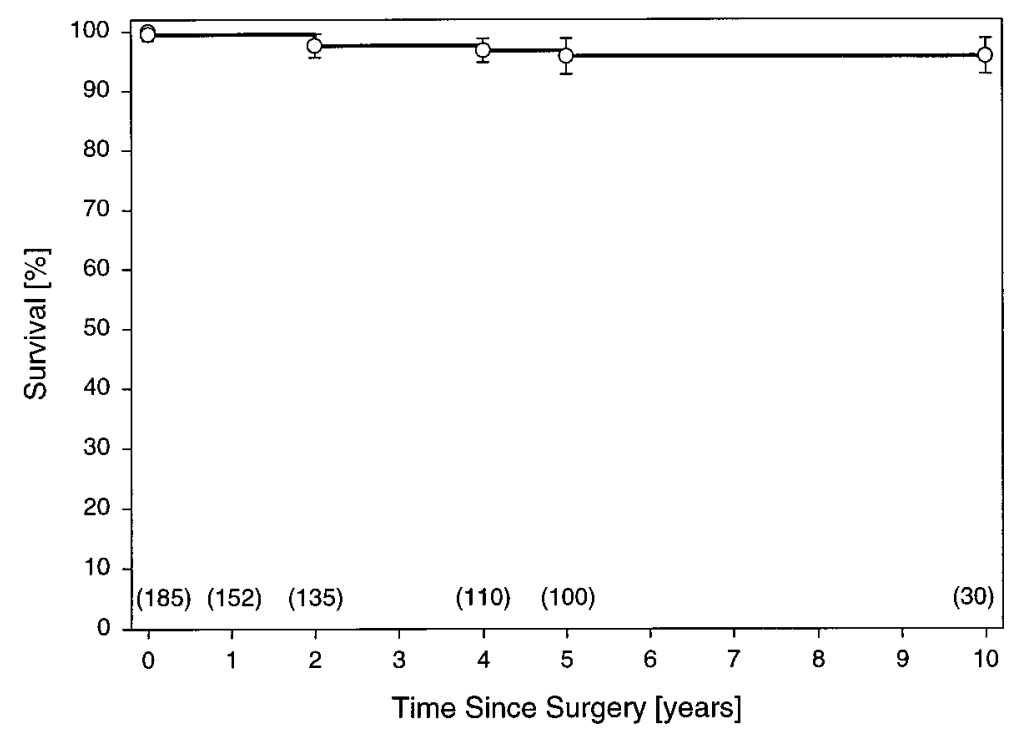

Fig 1. Kaplan-Meier actuarial survival for all 185 patients. Error bars indicate 95\% CIs based on the Greenwood formula. Estimated cumulative survival at 10 years was $96 \%$ (95\% CI, 93\%-99\%). The number of patients alive and at risk in the follow-up period are provided in parentheses at selected time points.

Table II. Multivariate risk factors for death and recoarctation on the basis of the Cox model

\begin{tabular}{lccccc}
\hline Risk factor & Coefficient & $S E$ & Hazard ratio & $95 \%$ CI & P value \\
\hline Death & & & & & \\
$\quad$ Arch hypoplasia & 4.50 & 1.10 & 89.9 & $12.7-631$ & $<.0001$ \\
$\quad$ Year of operation & -0.15 & 0.06 & 0.9 & $0.8-0.95$ & .02 \\
Recoarctation & & & & & \\
$\quad$ Arch hypoplasia & 2.75 & 1.08 & 15.5 & $0.2-110$ & .01 \\
$\quad$ Age (y) & -0.05 & 0.02 & 0.9 & $0.85-0.94$ & $<.001$ \\
$\quad$ Year of operation & -0.10 & 0.04 & 0.9 & $0.83-0.96$ & .03 \\
\hline
\end{tabular}

infants) variable, sex, year of operation, and weight as continuous variables, and surgeon, presence or absence of sepsis, associated cardiac anomalies, arch hypoplasia, and alprostadil (prostaglandin) infusion as categoric variables. A forward stepwise selection procedure was used to construct the final multivariate models, and a significance level of .05 was required for a variable to be retained as a risk factor in the model. The SAS software package version 6.12 was used for all statistical analysis (SAS Institute, Cary, NC).

\section{Results}

Early mortality. There were $6(3 \%)$ deaths within 30 days of the operation. Survival at 5 years was $98 \% \pm 2 \%$, and survival at 10 and 15 years was $96 \% \pm 2 \%$ (Fig 1). Results obtained by the Cox multivariate regression identified 2 independent risk factors associated with death: persistent arch hypoplasia after the operation $(P<$ $.0001)$ and year of operation $(P=.02)$. Because younger age as a continuous variable was found to be a risk fac- tor, this variable was categorized into 2 subgroups to compare neonates and infants. None of the other variables were found to be significant in the multivariate analysis $(P>.1$ in each case). Regression coefficients, SEs, hazard ratios, and 95\% CIs are shown in Table II. Four patients died on the first postoperative day. One died of persistent acidosis and low cardiac output. The second had an associated VSD and died of low cardiac output on the operating table. The third patient died of sudden bradycardia unresponsive to pharmacologic means a few hours after the operation, and the final patient had severe metabolic acidosis. Two further patients were unable to be weaned from the ventilator, and intractable respiratory failure developed.

Follow-up. At 5-year follow-up, of 179 patients, 146 $(82 \%)$ had undergone transthoracic echocardiography where systolic gradient and diastolic tail were assessed. A further 33 patients who had not had a transthoracic 


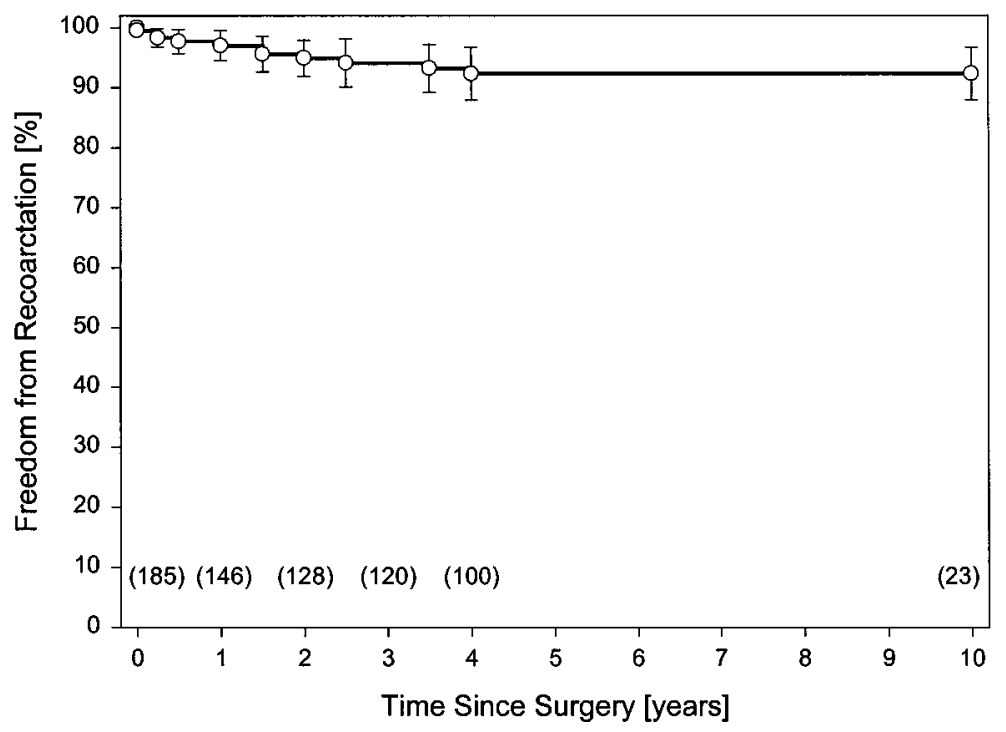

Fig 2. Kaplan-Meier actuarial freedom from recoarctation for all 185 patients. Error bars indicate $95 \%$ CIs based on the Greenwood formula. Estimated freedom from recoarctation at 10 years was $96 \%$ (95\% CI, 88\%-96\%). The numbers of patients remaining free from recoarctation and at risk in the follow-up period are provided in parentheses at selected time points.

echocardiogram in the follow-up period were contacted and called back for an echocardiogram. Fifty-one (28\%) patients underwent cardiac catheterization; 32 of these were performed in the first 5 years of the study. Seven $(4 \%)$ patients underwent magnetic resonance imaging.

Recoarctation. Eleven (6\%) patients had recoarctation after a median time of 6.2 years $(6.2 \pm 4.6$ years $)$. The freedom from recoarctation at 2 years was $95 \%$ (95\% CI, 92\%-98\%), and at 5, 10, and 15 years, it was 92\% (95\% CI, 88\%-96\%; Fig 2). This is also shown in Fig 3, where neonates and infants are compared. Results obtained by the Cox multivariable regression established 3 independent risk factors associated with recoarctation: persistent arch hypoplasia after the operation $(P=.01)$, year of operation $(P=.03)$, and age as a continuous variable $(P<.001)$. None of the other variables were significantly associated with recoarctation in the Cox multivariate analysis $(P>.1$ in each case). Regression coefficients, SEs, hazard ratios, and 95\% CIs are shown in Table II. As shown in Table II, the more recent operations, reflected by a negative coefficient and a hazard ratio of less than 1, are associated with lower risk of survival and recoarctation. The details of the 11 patients who had recoarctation and required reintervention are shown in Table III. Three patients had reoperation. Two of these had arch hypoplasia diagnosed preoperatively, and this was per-
Table III. Characteristics of patients with recoarctation of the aorta

\begin{tabular}{lll}
\hline $\begin{array}{l}\text { Patient } \\
\text { No. }\end{array}$ & $\begin{array}{c}\text { Preintervention } \\
\text { gradient, } \mathrm{mm} \mathrm{Hg}\end{array}$ & $\begin{array}{c}\text { Reintervention } \\
(\mathrm{F} / \mathrm{U})\end{array}$ \\
\hline 1 & $28(4 \mathrm{y})$ & Balloon $(10 \mathrm{y})$ \\
2 & $52(2.5 \mathrm{y})$ & Balloon $(10 \mathrm{y})$ \\
3 & $40(3 \mathrm{~d})$ & Operation $(12 \mathrm{y})$ \\
4 & $45(3 \mathrm{mo})^{*}$ & Balloon $(4 \mathrm{y})$ \\
5 & $70(1.5 \mathrm{y})$ & Balloon $(6.5 \mathrm{y})$ \\
6 & $42(2 \mathrm{y})^{*}$ & Balloon $(11 \mathrm{y})$ \\
7 & $44(3 \mathrm{mo})$ & Balloon $(3.5 \mathrm{y})$ \\
8 & $50(11 \mathrm{mo})$ & Operation $(5 \mathrm{y})$ \\
9 & $30(3.5 \mathrm{y})$ & Balloon $(5 \mathrm{y})$ \\
10 & $60(5 \mathrm{mo})$ & Operation $(3 \mathrm{y})$ \\
11 & $40(1.5 \mathrm{y})$ & Balloon $(1 \mathrm{y})$ \\
\hline
\end{tabular}

The preintervention gradient is obtained by Doppler echocardiography. $F / U$, Follow-up.

*Patients with two episodes of recoarctation. The gradients are before the second reintervention.

sistent at follow-up. However, the recoarctation was at the distal site of the anastomosis. Repair was performed by resection and end-to-end anastomosis. Eight underwent balloon dilatation. Follow-up was complete in all these patients, with a median time of 6.5 years (range, 1-11 years). In all patients after reintervention, the postintervention gradient was less than $20 \mathrm{~mm} \mathrm{Hg}$. This was demonstrated in all patients by transthoracic 


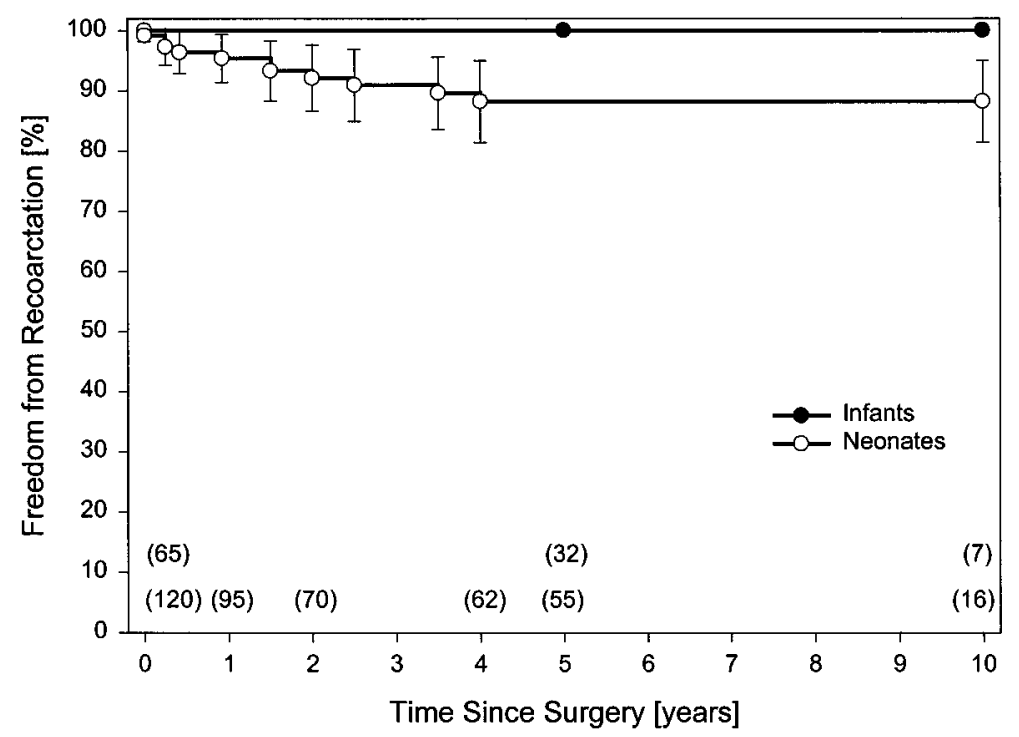

Fig 3. Kaplan-Meier estimated freedom from recoarctation according to age categorized into infants and neonates $(P=.01$; log-rank test, 6.17). Error bars indicate $95 \%$ CIs based on the Greenwood formula. The numbers of patients remaining free from recoarctation and at risk in the follow-up period are provided in parentheses at selected time points for infants (top row) and neonates (bottom row).

echocardiography and confirmed in 6 patients by means of aortography.

Patients with arch hypoplasia. Of the $41(22 \%)$ patients with a preoperative diagnosis of arch hypoplasia, $4(10 \%)$ had persistent arch hypoplasia diagnosed at $1.5,2,3$, and 8 years after the surgical treatment. In all 4 patients, cardiac catheterization was performed, and 2 patients also underwent magnetic resonance imaging.

Patients with VSDs. Of the $66(36 \%)$ patients with VSDs, 17 underwent pulmonary artery banding at the time of coarctation repair. Fifteen had a large VSD, 1 had multiple VSDs, and 1 had a moderate-sized VSD. The remainder were stable and did not require concomitant pulmonary artery banding. The small-sized VSDs in 38 of the 41 patients had closed spontaneously at a median follow-up of 4.3 years. All other patients underwent surgical closure.

Surgical complications. The left arm function was not assessed formally but rather on the basis of symptoms and general appearance. None of the patients had any neurologic or ischemic complications involving the left arm, either at early or late follow-up. None had aneurysm formation. One patient was hypertensive at follow-up, requiring medication.

\section{Discussion}

The optimal surgical management of coarctation remains controversial, despite more than 50 years of experience with treatment of this condition. The controversies concern several issues: (1) method of repair, (2) growth of the hypoplastic arch, (3) treatment of associated anomalies, and (4) incidence and assessement of recoarctation. All areas of contention are due in part to the lack of prospective randomized studies and in part to a lack of uniformity in defining recurrence of coarctation of the aorta and arch hypoplasia.

The aim of this study was not to compare different surgical methods for the repair of coarctation of the aorta. Our policy has been to perform SFA in all neonates and small infants. In addition to reporting outcomes, the particular concern of the study was to determine whether SFA would facilitate growth of the aortic arch without the need for surgical augmentation. Recent reports have shown a trend toward forms of end-to-end anastomosis for repair of coarctation of the aorta and highlighted the potential disadvantages of SFA. ${ }^{8}$ These include leaving the ductal tissue, which may contribute to subsequent recoarctation, the inability to relieve coexistent arch hypoplasia, the inherent disadvantage of having to sacrifice the left subclavian artery, and the possibility of an increased risk of late aneurysm formation in the abnormal tissue of the posterior aortic wall. However, these potential disadvantages are not borne out in the literature or in our data. Ziemer and colleagues ${ }^{9}$ reported on 100 patients, $70 \%$ of whom underwent SFA and $24 \%$ of whom underwent 
end-to-end anastomosis repair. Freedom from reintervention for recoarctation after 5 years was not significantly different between the 2 groups. Similarly, others have shown no difference in recoarctation rates between SFA and end-to-end anastomosis. ${ }^{10,11} \mathrm{We}$ report a recoarctation rate of $6 \%$. This is lower than other figures in the literature, which report rates from $9.8 \%{ }^{11}$ to $24 \% .^{9}$

It is unlikely that we have underestimated our incidence of recoarctation because 146 (81\%) patients underwent transthoracic echocardiography, with Doppler studies performed at the latest follow-up. Borderline cases were additionally investigated by angiography or magnetic resonance imaging. This differs from most other reports in which recoarctation was assessed by arm-leg blood pressure differences alone, and therefore in those series its incidence may have been underestimated.

One of the potential advantages of extended end-toend anastomosis repair is the ability to deal with arch hypoplasia at the time of presentation. ${ }^{12}$ This is clearly not the case with SFA, but adequate growth (presumably resulting from improved arch flow characteristics) was achieved in the vast majority of our patients. Nonetheless, arch hypoplasia persisted in $2 \%$ of the patients and was indeed identified as a risk factor for subsequent recoarctation, although no patients required arch augmentation. In these patients angiographic imaging of the aorta showed that recoarctation was not due to a hypoplastic transverse arch, and it was probably at the site of ductal tissue. On this basis, we concur with Sewers and colleagues ${ }^{11}$ that in the vast majority of patients, there is no need for extensive resection and aggressive enlargement of the hypoplastic arch.

As for the treatment of patients with an associated large or moderately large VSD, we have repaired the coarctation and undertaken pulmonary artery banding at the same time. A multi-institutional study demonstrated that among patients with coexisting moderateto large-sized VSDs, repair of coarctation of the aorta, pulmonary artery banding, and subsequent repair of the VSD were associated with the highest 2year survival (ie, $97 \%$ in those with a single VSD). ${ }^{13}$ In our study the patients with concomitant VSDs did not have a higher morbidity or mortality or reduced long-term survival when compared with those without a VSD.

We believe that SFA still provides an excellent method of repair for neonatal and infantile coarctation of the aorta. When properly performed in patients with simple additional defects, this technique gives rise to a low incidence of recoarctation, and adequate arch growth occurs without the need for augmentation.

We thank Ms Li Chung and Ms Andrea Mather for their invaluable assistance in collecting the data and organizing follow-up echocardiography.

\section{REFERENCES}

1. Gross RE, Hufnagel CA. Coarctation of the aorta: experimental studies regarding its surgical correction. $\mathrm{N}$ Engl $\mathrm{J}$ Med 1945;233:287-93.

2. Schuster SR, Gross RE. Surgery for coarctation of the aorta: a review of 500 cases. J Thorac Cardiovasc Surg 1962;43:54-70.

3. Waldhausen JA, Nahrwold DL. Repair of coarctation of the aorta with a subclavian flap. J Thorac Cardiovasc Surg 1966;51:532-3.

4. Carvalho J, Redington AN, Shinebourne EA, Rigby ML, Gibson D. Continuous wave Doppler and coarctation of aorta: gradients and flow patterns in the assessment of severity. Br Heart $\mathbf{J}$ 1990;76:133-7.

5. Moulaert AJ, Bruins CC, Oppenheimer-Dekker A. Anomalies of the aortic arch and ventricular septal defect. Circulation 1976;95:265-74.

6. Kaplan EL, Meier P. Nonparametric estimation from incomplete observations. J Am Stat Assoc 1058;53:457-81.

7. Cox DR. Regression models and life-tables. J R Stat Soc Series B 1972;34:187-202.

8. Jonas RA. Do we need to resect ductal tissue? Ann Thorac Surg 1991;52:604-7.

9. Ziemer G, Jonas RA, Perry SB, Freed MD, Castaneda AR. Surgery for coarctation of the aorta in the neonate. Circulation 1986;74(Suppl):I-25-31.

10. Knott-Craig CJ, Elkins RC, Ward KE, Overholt ED, Razoook JD, McCue CA, et al. Neonatal coarctation repair: influence of technique on late results. Circulation 1993;88(5 Pt 2):II-198-204.

11. Siewers RD, Ettedgui J, Pahl E, Tallman T, del Nido PJ. Coarctation and hypoplasia of the aortic arch: Will the arch grow? Ann Thorac Surg 1991;52:608-14.

12. Conte S, Lacour-Gayet F, Serraf A, Sousa-Uva M, Bruniaux J, Touchot A, et al. Surgical management of neonatal coarctation. J Thorac Cardiovasc Surg 1995;109:663-75.

13. Quaegebeur JM, Jonas RA, Weinberg AD, Blackstone EH, Kirklin JW. Outcomes in seriously ill neonates with coarctation of the aorta: a multiinstitutional study. J Thorac Cardiovasc Surg 1994;108:841-54. 